Published in final edited form as:

Nat Neurosci. 2007 February ; 10(2): 186-195. doi:10.1038/nn1837.

\title{
Retrograde modulation of presynaptic release probability through signaling mediated by PSD-95-neuroligin
}

\author{
Kensuke Futai ${ }^{1,2,3}$, Myung Jong Kim ${ }^{1,2}$, Tsutomu Hashikawa ${ }^{3}$, Peter Scheiffele ${ }^{4}$, Morgan \\ Sheng ${ }^{1,2}$, and Yasunori Hayashi ${ }^{1}$ \\ ${ }^{1}$ RIKEN-MIT Neuroscience Research Center, The Picower Institute for Learning and Memory, \\ Department of Brain and Cognitive Sciences, 77 Massachusetts Avenue, Cambridge, \\ Massachusetts 02139, USA \\ ${ }^{2}$ Howard Hughes Medical Institute, Department of Biology, Massachusetts Institute of \\ Technology, 77 Massachusetts Avenue, Cambridge, Massachusetts 02139, USA \\ ${ }^{3}$ Laboratory for Neural Architecture, Advanced Technology Development Group, Brain Science \\ Institute, RIKEN, 2-1 Hirosawa, Wako, Saitama, 351-0198, Japan \\ ${ }^{4}$ Department of Physiology and Cellular Biophysics, Center for Neurobiology and Behavior, \\ Columbia University, College of Physicians and Surgeons, P\&S 11-511, 630 West 168th Street, \\ New York, New York 10032, USA
}

\section{Abstract}

The structure and function of presynaptic and postsynaptic components of the synapse are highly coordinated. How such coordination is achieved and the molecules involved in this process have not been clarified. Several lines of evidence suggest that presynaptic functionalities are regulated by retrograde mechanisms from the postsynaptic side. We therefore sought postsynaptic mechanisms responsible for trans-synaptic regulation of presynaptic function at excitatory synapses in rat hippocampal CA1 pyramidal neurons. We show here that the postsynaptic complex of scaffolding protein PSD-95 and neuroligin can modulate the release probability of transmitter vesicles at synapse in a retrograde way, resulting in altered presynaptic short-term plasticity. Presynaptic $\beta$-neurexin serves as a likely presynaptic mediator of this effect. Our results indicate that trans-synaptic protein-protein interactions can link postsynaptic and presynaptic function.

The structure and function of synapses are highly heterogeneous, even among synapses formed on single neuron ${ }^{1-3}$. At the same time, pre-and postsynaptic structures and functions are well coordinated at the level of the individual synapse. For example, in excitatory synapses on hippocampal pyramidal cells, large postsynaptic dendritic spines have a larger postsynaptic density with more AMPA receptors (AMPARs) on their surface. At the same time, juxtaposing presynaptic terminals have a larger active zone and more docked

Reprints and permissions information is available online at http://npg.nature.com/reprintsandpermissions

Correspondence should be addressed to Y.H. (yhayashi@ mit.edu).

Competing Interests Statement: The authors declare that they have no competing financial interests.

Note: Supplementary information is available on the Nature Neuroscience website. 
vesicles $^{4-7}$. Such postsynaptic and presynaptic structural and functional coordination ensures more efficient transmission.

Presynaptic-postsynaptic coordination is probably a result of coordinated assembly of specific molecules on both sides of the synaptic cleft. What kinds of molecules are involved in that process, which side of the synapse 'instructs' the other, and what is the mechanism for that? There is evidence that the postsynaptic cell may be 'instructive' to presynaptic function. For example, in hippocampal slice preparations, analyses of connections made between a Schaffer collateral axon from a CA3 pyramidal neuron targeting CA1 pyramidal neurons or inhibitory interneurons indicate that the type of the postsynaptic target neuron can dictate the presynaptic properties ${ }^{8}$. Also, the amount of activity of postsynaptic neurons can change presynaptic properties. For example, in hippocampal dissociated culture, increasing the postsynaptic activity of calmodulin-dependent protein kinase II (CaMKII) by transfecting its active forms remodels presynaptic input by increasing the number of synaptic contacts between pairs of neuron but decreasing the total number of connected cells ${ }^{9}$. Similar retrograde action of CaMKII is also reported in drosophila ${ }^{10,11}$. Those observations exemplify the ability of a postsynaptic neuron to influence functional properties of the presynaptic terminal in a retrograde way.

In this study, we sought the mechanism involved in the retrograde regulation of presynaptic release probability, which is a chief determinant of presynaptic functionality such as frequency facilitation and depression, augmentation and post-tetanic potentiation, collectively called 'short-term plasticity' ${ }^{12}$. Because of that feature, each individual presynaptic terminal serves as an independent functional unit that transmits a presynaptic action potential firing pattern in a different efficiency to the postsynaptic side according to the release probability.

Postsynaptic scaffolding protein PSD-95 and one of its binding partners, neuroligin (NLG), connect postsynaptic density to the presynaptic release machinery through a trans-synaptic interaction mediated by the extracellular domains of NLG and that of its presynaptic binding partner, $\beta$-neurexin $(\beta \mathrm{Nrxn})^{13-20}$. Intracellularly, $\beta \mathrm{Nrxn}$ binds to the PDZ (PSD-95-discs large-zona occludens-1) domain of the scaffolding protein CASK (mLin-2), which then recruits proteins of the presynaptic release machinery to initiate the assembly of a presynaptic active zone ${ }^{18-20}$. CASK links the NLG- $\beta$ Nrxn complex to synaptic vesicle trafficking by binding to the scaffolding protein Mint1 (X11), which directly interacts with Munc18, a functional regulator of neurotransmitter release. In that way, the postsynaptic PSD-95-NLG complex assembles presynaptic release machinery to the presynaptic terminal through the NLG-PNrxn interaction.

The PSD-95-NLG- $\beta$ Nrxn interaction provides a likely candidate mechanism for the postsynaptic regulation of presynaptic functionality. Here we demonstrate that the postsynaptic PSD-95-NLG complex modulates the release probability of presynaptic terminals in a retrograde way by increasing sensitivity to extracellular calcium $\left(\mathrm{Ca}^{2+}\right)$. That effect is probably mediated by presynaptic $\beta$ Nrxn. Postsynaptic PSD-95 is involved in the recruitment of AMPARs to the postsynaptic membrane through an interaction with 
postsynaptic proteins of the stargazin family $16,21-23$. Thus, through NLG and $\beta$ Nrxn, PSD-95 can modulate synaptic transmission by presynaptic as well as postsynaptic actions.

\section{Results}

Postsynaptic PSD-95 modulates the paired-pulse ratio In hippocampal slice cultures, CA1 neurons overexpressing PSD-95 had a much higher amplitude of AMPAR-mediated excitatory postsynaptic current (AMPAR-EPSC) than did neighboring untransfected cells (Fig. 1a-e). That finding has been explained mainly by postsynaptic insertion of additional AMPARs in published electrophysiological and cell biological studies ${ }^{16,21-23}$. We wondered if such PSD-95 mediated potentiation is due in part to an increased probability of presynaptic glutamate release. Consistent with the presynaptic change, it has been reported that the miniature EPSC frequency increases in cells overexpressing PSD-95 (refs. 16,21), but such an increase may also reflect postsynaptic effects, such as an increase in the total number of synapses or the 'unsilencing' of silent synapses. We therefore measured the paired-pulse ratio (PPR) of the AMPAR-EPSC, a form of presynaptic short-term plasticity inversely correlated with release probability in general (Fig. 1d,e) $)^{2,12}$. The PSD-95 transfected cells had significantly less PPR than did untransfected neurons, suggesting that release probability is enhanced by postsynaptically expressed PSD-95.

If PSD-95 changes the properties of AMPAR, such as desensitization, we might find an apparent change in the PPR by a postsynaptic mechanism. To rule out such a possibility, we measured the PPR of the NMDA receptor-mediated EPSC (NMDAR-EPSC) as well. Postsynaptic expression of PSD-95 weakly but significantly increased the amplitude and decreased the PPR of the NMDAR-EPSC, similar to its effects on the AMPAR-EPSC (Fig. $1 \mathrm{c}$ and e). Such a parallel change of the PPR in both the AMPAR-ESPC and NMDAREPSC rules out the possibility of modulation of the AMPAR or NMDAR itself as a putative cause and supports the view that the change is presynaptic. The PPR of the NMDAR-EPSC was consistently smaller than that of the AMPAR-EPSC. It has been reported that whereas NMDARs exist in almost all excitatory synapses, AMPARs tend not to exist in smaller dendritic spines ${ }^{24}$. Such heterogeneity in the populations of synapses may explain the difference in the PPR of the two components. Another possibility is that the difference in the saturation of the two types of receptors by glutamate in the synaptic cleft can account for the difference.

We next tested the effect of the downregulation of PSD-95 using RNA interference (RNAi; Fig. 1f-j). We confirmed the efficacy of the knockdown by the short hairpin RNA (shRNA) in Cos7 cells and cultured hippocampal dissociated neurons (Supplementary Fig. 1 online). In contrast to the result of overexpression, downregulation of PSD-95 led to an increase in the PPR, as well as significant reductions in the amplitude of both the AMPAR-EPSC and NMDAR-EPSC. In sum, our results indicate that the amount of postsynaptic PSD-95 in CA1 pyramidal neurons can modulate the presynaptic release probability.

In routine experiments, we included 2-chloroadenosine, an agonist of the adenosine $\mathrm{A}_{1}$ receptor, in the extracellular solution to prevent bursting of the slice culture. To rule out the possibility that the effect of PSD-95 involves $\mathrm{A}_{1}$ receptor signaling, we omitted 2- 
chloroadenosine and used the AMPAR antagonist NBQX to block the bursting activity. In those conditions, we also noted an effect of postsynaptic PSD-95 on the NMDAR-EPSC PPR (PSD-95-transfected cells, $0.79 \pm 0.05$; untransfected cells, $1.05 \pm 0.07 ; n=13$ cell pairs; $P<0.01$ ), thus excluding the possibility of involvement of $\mathrm{A}_{1}$ adenosine receptormediated signaling in the effect of PSD-95.

\section{MK-801 confirms the modulation of release probability by PSD-95}

To further confirm our finding of retrograde regulation of presynaptic release probability in an independent assay, we used MK-801, an open-channel blocker of the NMDAR ${ }^{3}$. In the presence of MK-801, NMDAR-mediated transmission is blocked in a stimulus-dependent way; that occurs at a faster rate at synapses with higher release probability and at a slower rate at synapses with lower release probability. The rate of block of NMDAR-EPSC was significantly faster in cells overexpressing PSD-95 than in untransfected cells, consistent with an increase in channel opening and, hence, in the release probability of the presynaptic terminal (Fig. 2a-c). Conversely, cells expressing PSD-95 shRNA had a slower block of NMDAR-EPSCs than did untransfected cells, indicating a reduction in release probability (Fig. 2d-f). We could potentially explain those effects by a change in the ratio of receptors containing NMDAR subunit NR2A to those containing NR2B, because NR2B-containing receptors have longer open times than do NR2A-containing receptors ${ }^{25}$. We ruled out that effect here because the difference in the NMDAR-EPSC decay time constant $(\tau)$ was not significant (PSD-95-transfected cells, $\tau=90.1 \pm 3.3 \mathrm{~ms}$, untransfected cells, $\tau=85.2 \pm 3.2$ $\mathrm{ms}, P=0.29$ (41 cell pairs); PSD-95 shRNA-expressing cells, $\tau=120.1 \pm 6.7 \mathrm{~ms}$, untreated cells, $\tau=106.6 \pm 6.1 \mathrm{~ms}, P=0.15$ (11 cell pairs); single-exponential fit).

\section{Sensitivity of release machinery to extracellular $\mathrm{Ca}^{2+}$}

We next tested if that increase in release probability by postsynaptic overexpression of PSD-95 was due to an increase in the sensitivity of the release machinery to extracellular $\mathrm{Ca}^{2+}$. To test that, we increased the concentration of extracellular $\mathrm{Ca}^{2+}$ from $1 \mathrm{mM}$ to 10 $\mathrm{mM}$ and assessed the dose-response relationship of the NMDAR-EPSC amplitude (Fig. 3ac). The curve shifted toward a lower concentration of extracellular $\mathrm{Ca}^{2+}$ for PSD-95transfected cells than for untransfected cells (effective concentration for half-maximum response $\left(\mathrm{EC}_{50}\right)$ for $\mathrm{Ca}^{2+}, 2.20 \mathrm{mM}$ for PSD-95-transfected cells and $2.81 \mathrm{mM}$ for untransfected cells; Hill coefficient, 0.70 and 0.73 ). That result indicated that the sensitivity of presynaptic release to extracellular $\mathrm{Ca}^{2+}$ was increased by postsynaptic overexpression of PSD-95 (Fig. 3c).

At $1 \mathrm{mM} \mathrm{Ca}{ }^{2+}$, PSD-95-transfected neurons had an NMDAR-EPSC amplitude 2.7-fold greater than that of neighboring untransfected cells. As we increased the release probability by raising the $\mathrm{Ca}^{2+}$ concentration, the difference became smaller and dropped toabout 1.2fold at $10 \mathrm{mM}$, the highest concentration tested here (Fig. 3c). That is most easily explained if we assume the increase in NMDAR-EPSC amplitude was mediated mainly by an increase in transmitter release from the presynaptic terminals rather than being due to postsynaptic factors. At higher extracellular $\mathrm{Ca}^{2+}$ concentrations, the release probability becomes close to the saturation and, therefore, an increase in release probability due to postsynaptic PSD-95 was occluded. If the increase in the NMRAR-EPSC were due to a postsynaptic factor such 
as recruitment of the receptor, the effect should have been constant across different $\mathrm{Ca}^{2+}$ concentrations. In contrast, for AMPAR-EPSCs, both an increase in transmitter release and in postsynaptic sensitivity due to the addition of AMPARs contribute to the increase in EPSC amplitude ${ }^{16,21-23}$. That explains why the overall effect on amplitude was greater for AMPAR-EPSCs than for NMDAR-EPSCs (Fig. 1b,c). The relatively small effect of PSD-95 on NMDAR-EPSC amplitude has not been found in other laboratories ${ }^{21,23}$. That discrepancy may be in part explained by differences in basal release probability in slightly different experimental conditions among laboratories.

In hippocampal Schaffer collateral-CA1 synapses, N-type and P/Q-type subtypes of voltage-gated $\mathrm{Ca}^{2+}$ channels are the dominant presynaptic $\mathrm{Ca}^{2+}$ channel subtypes. It has been shown that PPR is modulated differently by selective blockade of individual $\mathrm{Ca}^{2+}$ channel subtypes ${ }^{26}$. We therefore used subtype-specific blockers to test if postsynaptic PSD-95 modifies the contribution of different subtypes of presynaptic $\mathrm{Ca}^{2+}$ channels to transmitter release. The $\mathrm{N}$-type $\mathrm{Ca}^{2+}$ blocker $\omega$-conotoxin GIVA moderately suppressed synaptic transmission (remaining NMDA-EPSC amplitude (\%): transfected cells, $59.5 \pm 2.9$; untransfected cells, $51.5 \pm 2.3$; data not shown), whereas the P/Q-type $\mathrm{Ca}^{2+}$ channel blocker $\omega$-agatoxin TK strongly suppressed transmission (remaining NMDA-EPSC amplitude (\%): transfected cells, $17.2 \pm 2.4$; untransfected cells, $16.0 \pm 2.3$; data not shown), and the effects were not significantly different $(P>0.05)$ for PSD-95-transfected and untransfected cells. That result indicated that the relative contributions of different presynaptic $\mathrm{Ca}^{2+}$ channel subtypes were not changed by postsynaptic overexpression of PSD-95.

\section{PSD-95 increases the cleft concentration of glutamate}

Studies have shown that in some circumstances, Schaffer collateral axon terminals can release multiple vesicles per action potential ${ }^{4,27,28}$. As postsynaptic AMPARs are not saturated, the cleft concentration of glutamate and the number of vesicles released per action potential at each synapse could be one site of regulation ${ }^{1}$. We therefore tested if PSD-95 increased the number of synaptic vesicles released per action potential in each synapse. We used a low-affinity competitive antagonist for AMPAR, $\gamma$-D-glutamylglycine $(\gamma$-DGG), which has rapid equilibration kinetics and competes with synaptically released glutamate for the ligand-binding sites on the AMPAR ${ }^{1,28}$. Because of that, AMPAR-mediated responses at synapses with lower glutamate concentrations are more effectively blocked by $\gamma$-DGG than are those at synapses with higher glutamate concentrations. The inhibition of the AMPAREPSC by $2 \mathrm{mM} \gamma$-DGG was significantly less in PSD-95-expressing neurons than in untransfected neurons (Fig. 3d,e), indicating that the cleft glutamate concentration is higher in synapses in which PSD-95 is overexpressed postsynaptically. The most likely cause is release of more vesicles on average at synapses overexpressing PSD-95, although other mechanisms, such as an increase in the concentration of glutamate in individual synaptic vesicles or impaired reuptake of released glutamate from the cleft, cannot be ruled out.

\section{NLG mediates the effect of PSD-95}

Given that PSD-95 is an intracellular protein, there should be a mechanism that conveys information in a retrograde way to the presynaptic side. We hypothesized that NLG might have such a function. NLG is a transmembrane protein with an extracellular domain that 
binds to presynaptic $\beta \mathrm{Nrxn}$ and an intracellular carboxyl terminus that binds to the PDZ domain 3 of PSD-95 (refs. 13,15,20). It has been reported that overexpression of NLG in postsynaptic neurons triggers the formation of functional presynaptic terminals in contacting axons by attracting presynaptic proteins ${ }^{14,17,20}$. Therefore, it is plausible that PSD-95 regulates presynaptic functionality through protein interaction mediated by NLG.

By overexpressing NLG1 in neurons, we found enhancement of AMPAR-EPSC and NMDAR-EPSC amplitude and a reduction in the PPR similar to that obtained with PSD-95 (Fig. 4a-e). 'Knockdown' of endogenous NLG1 by RNAi did not have a significant effect on EPSC amplitude and PPR compared with control untransfected neurons (Fig. 4f-j). That lack of effect may have been due to redundancy of other NLG subtypes, such as NLG2 and NLG3. We therefore attempted to block all endogenous NLG subunits by using a dominant negative construct in which the extracellular cholinesterase domain of NLG was 'swapped' with that of acetylcholinesterase itself (NLG1-SWAP), which does not interact with $\beta \mathrm{Nrxn}^{17}$. We expected that NLG1-SWAP would have dominant negative effect on all subtypes of NLGs because it competes with wild-type NLG for PSD-95 through the consensus PDZ domain-binding motif (-HSTTRV) at the very carboxyl end ${ }^{13,29}$. Overexpression of NLG1-SWAP significantly decreased the amplitude of both the AMPAREPSC and NMDAR-EPSC and consistently increased the PPR of both the AMPAR-EPSC and NMDAR-EPSC (Fig. 4k-o). That confirmed that endogenous postsynaptic NLG is needed to maintain presynaptic release probability.

To test if the observed effect of PSD-95 was in fact mediated by NLG1, we attempted to block the effect of PSD-95 by suppressing the expression or function of NLG. We first overexpressed PSD-95 while disrupting NLG1 function with RNAi or NLG1-SWAP (Fig. $5 \mathrm{a}-\mathrm{j}$ ). In both cases, the effect of PSD-95 on PPR was eliminated. The result of NLG1 RNAi in the presence of overexpressed PSD-95 seems contradictory to the effect of NLG1 RNAi by itself (Fig. 4i,j), which did not change the PPR. That is probably because overexpressed PSD-95 requires more NLG molecules, a requirement that could not be met by the remaining amount of NLG subtypes.

In the converse experiment, we overexpressed NLG1 while simultaneously 'downregulating' PSD-95 by RNAi. 'Downregulation' of PSD-95 blocked the effect of NLG1 on PPR (Fig. 5k-o). Those results indicate that PSD-95 and NLG1 are mutually dependent in exerting the retrograde effect on release probability, which is most simply explained by a requirement that NLG and PSD-95 form a protein complex at the postsynaptic membrane. NLG requires oligomerization and clustering to exert its activity, which may be one reason why the PSD-95-NLG1 complex seems to be necessary ${ }^{18}$. Unexpectedly, the enhancing effects of PSD-95 or NLG1 on the amplitude of AMPAR were abolished by downregulation of NLG or PSD-95, respectively. Although the mechanism for that is not clear, the result suggests that the formation of a complex of PSD-95 and NLG is required even for functional recruitment of postsynaptic AMPARs.

\section{$\beta$ Nrxn is a possible presynaptic mediator}

The extracellular domain of postsynaptic NLG binds to $\beta$ Nrxn, which is localized presynaptically. Is presynaptic $\beta$ Nrxn a mediator of the effect of postsynaptic PSD-95-NLG 
on transmitter release? We wanted to manipulate the function of $\beta \mathrm{Nrxn}$ specifically at the presynaptic side. However, the low probability of connection between given CA3 and CA1 pyramidal cells makes it impractical to find a presynaptic CA3 neuron linked synaptically to a postsynaptic CA1 neuron. We therefore turned to synaptic transmission between pairs of CA3 pyramidal neurons that are monosynaptically connected to one another through an intrinsic associational circuit at a relatively high probability ${ }^{30,31}$. CA3-CA3 synapses share many properties with Schaffer collateral-CA1 synapses, such as NMDAR-dependent plasticity ${ }^{30,31}$. In this system, we can 'patch on' to two nearby CA3 pyramidal cells and use one as the presynaptic cell and the other as the postsynaptic neuron.

We first confirmed that the effects of postsynaptic overexpression and downregulation of PSD-95 or NLG were similar on CA3-CA3 synaptic connections and on Schaffer collateral-CA1 synapses (Fig. 6). Indeed, the postsynaptic CA3 neurons transfected with PSD-95 had significantly larger AMPAR-mediated responses and smaller PPRs than did neurons expressing only green fluorescent protein (GFP). Both 'downregulation' of PSD-95 by RNAi and expression of NLG1-SWAP significantly increased the PPR of the AMPAREPSC and slightly decreased the EPSC amplitude, though the latter effect did not reach statistical significance (Fig. 6c,d). We then took advantage of the unitary nature of the connection and analyzed the success or failure rate of synaptic transmission (Fig. 6e). The success rate was significantly higher in cells postsynaptically overexpressing PSD-95 or NLG1 and lower in cells in which PSD-95 or NLG1 were downregulated. That result supports the idea that release probability is regulated by postsynaptic PSD-95 and NLG1.

We then transfected CA3 neurons with wild-type $\beta \mathrm{Nrxn}$ or its dominant negative form lacking the carboxy-terminal sequence $(\beta \mathrm{Nrxn} \Delta \mathrm{C})$ and stimulated them as presynaptic cells while recording EPSCs from adjacent, untransfected neurons that were postsynaptic (Fig. 7). Expression of these constructs in the presynaptic terminal has been confirmed before ${ }^{18}$. The neuronal pairs overexpressing $\beta$ Nrxn presynaptically had transmission amplitudes, PPR and a success rate similar to those of untransfected pairs (data not shown) or pairs expressing GFP presynaptically (Fig. 7); thus, presynaptic overexpression of $\beta \mathrm{Nrxn}$ by itself has no effect on synaptic transmission. In contrast, the dominant negative form $\beta \mathrm{Nrxn} \Delta \mathrm{C}$ significantly increased the PPR of expressing neurons and reduced the success rate (Fig. 7d,e). It also reduced the EPSC amplitude (Fig. 7c), although that reduction did not reach statistical significance. Those data suggest that presynaptic $\beta \mathrm{Nrxn}$ is required for maintaining release probability and may serve as the presynaptic binding partner that mediates the effect of postsynaptic PSD-95 and NLG on release probability.

\section{Discussion}

Despite many lines of evidence indicating the trans-synaptic coordination of pre- and postsynaptic structure and function, only a few molecules and mechanisms have been identified. Studies have shown that diffusible molecules, such as cannabinoid ${ }^{32}$, act as retrograde regulators of presynaptic functionality. In addition, trans-synaptic signaling mediated by postsynaptic integrin, Eph-ephrin, $\mathrm{N}$-cadherin and the scaffolding protein SAP97 has also been shown to regulate presynaptic release machinery in a retrograde way $^{33-36}$. In this study, we have identified a series of trans-synaptic protein-protein 
interactions mediated by postsynaptic PSD-95-NLG and presynaptic $\beta$ Nrxn, which control presynaptic release probability in a retrograde way.

\section{PSD-95- and NLG-mediated trans-synaptic signaling cascade}

It has been demonstrated that overexpression of postsynaptic PSD-95 and its binding partner NLG causes an accumulation of presynaptic proteins such as synaptophysin and bassoon in contacting axons, as measured by immunostaining of dissociated hippocampal neurons ${ }^{14,16,17,36}$ (M.J.K. and M.S., unpublished data). Conversely, triple-knockout mice lacking NLG1, NLG2 and NLG3 have lower expression of presynaptic proteins such as synaptobrevin-2, synaptophysin-1, VGluT1 and synaptotagmin-1, along with much lower synaptic trans-mission ${ }^{37}$. In that way, the postsynaptic PSD-95-NLG complex recruits presynaptic proteins to the axon terminals. Those findings are consistent with our functional data showing that the postsynaptic PSD-95 increases the number of vesicles released per action potential, which is probably the basis of the observed change in PPR.

However, overexpression of PSD-95 and NLG1 not only causes an accumulation of postsynaptic proteins but also promotes the formation of new synapses in dissociated cultures ${ }^{14,16}$. Such synapses may have higher probability of release, resulting in a net decrease in the PPR without affecting existing synapses. Therefore, it is important to know whether the observed effect of PSD-95 and NLG involves the generation of new synapses. It has been reported that in slice cultures, the number of dendritic spines is not increased by PSD-95 overexpression ${ }^{21}$. Also, we found only a modest increase in the amplitude of NMDAR-EPSC by overexpression of PSD-95 (Fig. 1a,c). That was mostly abrogated by increasing the release probability by raising the extracellular $\mathrm{Ca}^{2+}$ (Fig. 3a-c), indicating that the locus of the effect was mainly presynaptic. From those lines of evidence, we consider that the observed effect of PSD-95 and NLG in our preparation was not secondary to the generation new synapses. Furthermore, the effect of downregulation of endogenous PSD-95 and NLG by RNAi or a dominant negative construct was opposite to the effect of overexpression (Figs. 1,2,4,6). Consistent with that, knockout mice with partially deleted PSD-95 have an increased PPR ${ }^{38}$. Thus, endogenous PSD-95 and NLG are necessary for maintaining presynaptic release probability.

\section{Possible function of $\beta$ Nrxn as a binding partner of PSD-95-NLG}

$\beta \mathrm{Nrxn}$ is an established presynaptic binding partner for postsynaptic NLG. Indeed, overexpression of $\beta \mathrm{Nrxn}$ induces more presynaptic structure in dissociated cultures ${ }^{18-20}$. In our system, downregulation of $\beta \mathrm{Nrxn}$ decreased the probability of release (Fig. 7). Intracellularly $\beta \mathrm{Nrxn}$ binds to the PDZ domain of CASK. CASK then links $\beta \mathrm{Nrxn}$ to synaptic vesicle trafficking by binding with Mint1 (X11), which directly interacts with Munc18, a functional regulator of neurotransmitter release ${ }^{20}$. That interaction may organize the presynaptic release machinery by coordinating with postsynaptic PSD-95-NLG.

Overexpression of $\beta \mathrm{Nrxn}$ did not increase the release probability or EPSC amplitude, unlike postsynaptic overexpression of PSD-95 or NLG. We can think of two possible, not mutually exclusive, explanations for that. One explanation is that postsynaptic PSD-95-NLG is limited in quantity, whereas presynaptic $\beta \mathrm{Nrxn}$ exists in redundancy and such excess $\beta \mathrm{Nrxn}$ 
is nonfunctional. Therefore, an increase in presynaptic $\beta$ Nrxn does not have effect, unlike postsynaptic over-expression of PSD-95 or NLG1. The second explanation is as follows. When PSD-95 or NLG1 are overexpressed postsynaptically their effect is limited to presynaptic termini directly opposite the neuron, which is a small fraction compared with the total number of synapses formed on an axon. In that case, $\beta \mathrm{Nrxn}$ at those synapses can efficiently exerts its effect by recruiting its intracellular binding partner (such as CASK) and eventually the vesicle-release machineries. In contrast, when $\beta \mathrm{Nrxn}$ is overexpressed presynaptically it overwhelms in all presynaptic termini in the transfected neuron. That may cause competition among synapses for the binding partners involved in vesicle release machinery, resulting in a lack of effect of overexpressed $\beta \mathrm{Nrxn}$ in any synapse.

An experiment using a low-affinity antagonist to AMPAR indicated an increase in the concentration of glutamate in clefts of neurons overexpressing PSD-95 (Fig. 3d,e). Although several scenarios are still possible to explain that observation, in combination with other evidence provided here (such as the PPR; Fig. 1e), the relationship of $\mathrm{Ca}^{2+}$ concentration and EPSC amplitude (Fig. 3a-c) and the analysis of the successful or failure of transmission (Fig. 6e), the most plausible explanation is an increased release of synaptic vesicles by action potential. At present, we do not know whether the effect of the PSD-95-NLG- $\beta$ Nrxn complex on the release machinery is quantitative or qualitative; the $\beta \mathrm{Nrxn}$-mediated protein interaction may accumulate many synaptic vesicles in the readily releasable pool by increasing the number of release sites. Alternatively, $\beta \mathrm{Nrxn}$ may increase the release probability of individual vesicles.

In addition to $\beta N r x n$, hippocampal neurons express the larger aNrxn isoform from an alternative transcription start site. It has been shown that aNrxn regulates voltage-gated $\mathrm{Ca}^{2+}$ channels and is therefore involved in the regulation of transmitter release ${ }^{20,39,40}$. The involvement of aNrxn in retrograde control of release machinery is an intriguing issue. However, the NLG1 we used in this study does not bind to aNrxn ${ }^{41}$ but still fully exerts its effects. Therefore, the effects of NLG1 noted in our assays do not require direct interaction with presynaptic aNrxn.

\section{Functional importance of trans-synaptic signaling}

PSD-95-mediated pre- and postsynaptic modulation may be involved in the coordination of pre- and postsynaptic functions during development and plasticity. During the development of hippocampus, as the expression PSD-95 and NLG increases, the PPR of Schaffer collateral fiber-CA1 decreases ${ }^{42-44}$. However, it has been shown that PSD-95 increases postsynaptic responsiveness by recruiting AMPARs ${ }^{16,21-23}$. PSD-95 is acutely translocated to the synaptic contact by neuronal activity in visual cortex ${ }^{45}$, where it may be involved in the coordinated development of both sides of synapse.

In addition, retrograde modulation of the release probability is important in determining neural network properties. For example, a Schaffer collateral fiber demonstrates different features of short-term plasticity depending on its postsynaptic targets ${ }^{8}$. That is explained in part by the lower release probability at synapses on pyramidal neurons than at those on interneurons. That type of target cell specificity of presynaptic functionality is found in other 
regions of hippocampus and cortex as well ${ }^{46,47}$. Along with our findings, it may suggest that the amount of postysynaptic PSD-95-NLG determines presynaptic functionality.

In addition to presynaptic short-term plasticity, a retrograde mechanism may mediate presynaptic structural plasticity. Rapid and persistent expansion of postsynaptic dendritic spines by stimulation inducing long-term potentiation has been shown ${ }^{48,49}$. In brain tissue, there is good correlation between the size of the presynaptic and postsynaptic structures. That indicates that postsynaptic expansion of the dendritic spine must be accompanied by a presynaptic structural change at some point. A study using electron microscopy has found transient disparity between pre- and postsynaptic dimensions immediately after the induction of long-term potentiation, which is gradually diminished with enlargement of the presynaptic side over a time course of hours ${ }^{50}$, indicating a mechanism that coordinates postsynaptic and presynaptic morphology. Synaptic recruitment of PSD-95 after the onset of the activity ${ }^{45}$ and trans-synaptic signaling via NLG- $\beta$ Nrxn could contribute to such a matching process.

\section{Methods}

\section{Expression vectors}

Expression vectors have been reported for untagged PSD-95 (ref. 22), vesicular stomatitis virus-tagged $\beta \mathrm{Nrxn}$ and $\beta \mathrm{Nrxn} \Delta \mathrm{C}^{18}$ and NLG1 RNAi ${ }^{14}$. We subcloned hemagglutinintagged NLG1 containing splice insertions $\mathrm{A}$ and $\mathrm{B}^{17}$ under control of the $\mathrm{CAG}$ promoter. For the PSD-95 shRNA construct, we annealed the following oligonucleotides and inserted them between the HindIII and BglII sites of the pSUPER vector: $5^{\prime}$ -

GATCCCCGAGGCAGGTTCCATCGTTCTTCAAGAGAGAACGATGGAACCT GCCTCTTTTT-3'; and 5'-AGCTAAAAAGAGGCAGGTTCCATCGTTCTCTCT TGAAGAACGATGGAACCTGCCTCGGG-3'

\section{Simultaneous recording from two neighboring hippocampal CA1 pyramidal cells}

Guidelines of the Massachusetts Institute of Technology were followed for all experiments involving animals. We made electrophysiological recordings from organotypic hippocampal slice cultures (days 7-11 in vitro) as described ${ }^{22}$. We transfected neurons on days 3-6 in vitro using a biolistic gene gun (BioRad). We used $100 \mathrm{mg}$ DNA and $12.5 \mathrm{mg}$ gold particles ( $1.6 \mu \mathrm{m}$ in diameter) to make about 50 bullets. The extracellular solution was as follows (in $\mathrm{mM}): 119 \mathrm{NaCl}, 2.5 \mathrm{KCl}, 4 \mathrm{CaCl}_{2}, 4 \mathrm{MgCl}_{2}, 26 \mathrm{NaHCO}_{3}, 1 \mathrm{NaH}_{2} \mathrm{PO}_{4}, 11$ glucose, 0.15 picrotoxin (Sigma) and 0.01 2-chloroadenosine (ICN), gassed with $5 \% \mathrm{CO}_{2}$ and $95 \% \mathrm{O}_{2}$, $\mathrm{pH} 7.4$, unless otherwise noted. The NMDAR-EPSC was measured in the presence of NBQX (0.01 mM; Tocris). When we used $\omega$-agatoxin TK ( $200 \mathrm{nM}$; Peptide Institute) or $\omega$ conotoxin GVIA ( $2 \mu \mathrm{M}$; Peptide Institute), we dissolved them in extracellular solution containing cytochrome C $(0.1 \mathrm{mg} / \mathrm{ml}$; Sigma) immediately before application. We used MK-801 (40 $\mu \mathrm{M}$; Tocris) to estimate release probability in Figure 2. We made whole-cell recordings simultaneously from a pair of CA1 pyramidal neurons, one transfected (visualized by cotransfection of GFP) and one untransfected neighbor. We filled the patch recording pipettes (2-5 M $\Omega$ ) with internal solution containing the following (in $\mathrm{mM}$ ): 115 cesium methanesulfonate, $20 \mathrm{CsCl}, 10$ HEPES, $2.5 \mathrm{MgCl}_{2}$, 4 ATP disodium salt, 0.4 
guanosine triphosphate trisodium salt, 10 sodium phosphocreatine and 0.6 EGTA, at $\mathrm{pH}$ 7.25, with $\mathrm{CsOH}$ unless otherwise specified. For NMDAR-EPSC recordings at different extracellular calcium concentrations (Fig. 3), we substituted EGTA with the $\mathrm{Ca}^{2+}$ chelator BAPTA $(10 \mathrm{mM})$ to suppress $\mathrm{Ca}^{2+}$-dependent inactivation of NMDAR. We evoked 40-50 consecutive synaptic responses at $0.2 \mathrm{~Hz}$ with a stimulating electrode placed in the stratum radiatum while holding the neuron at $\mathrm{V}_{\text {hold }}=-60 \mathrm{mV}$ for AMPAR-EPSC and at $+40 \mathrm{mV}$ for NMDAR-EPSC. We measured the PPR of synaptic responses by delivering two afferent stimulations (50-ms interstimulus interval). As the transmission of the AMPAR-EPSC became much larger with transfection of PSD-95 and NLG1, to rule out the possibility of a systematic voltage-clamping error, we reduced the stimulation intensity in some cell pairs so that the transfected cells would have response amplitudes comparable to those of the untransfected cells. In those conditions, we still found a consistent reduction in PPR in transfected cells, thus ruling out the possibility of a voltage-clamping error. We discarded cell pairs with a difference in series resistance of more than $20 \%$. We did experiments 'blinded' to the DNA constructs used. As we made recordings from neurons expressing wild-type PSD-95 in an overlapping period, we shared the data in Figure 1a-c with other projects $^{22}$ (M.J.K. et al., unpublished data). We evaluated statistical significance with the Kruskal-Wallis analysis of variance for multiple comparisons, the Mann-Whitney test for EPSC amplitude comparison and Student's $t$-test for PPR and time constant comparison. We set statistical significance at $P$ values of less than 0.05 . We fitted the $\mathrm{Ca}^{2+}$ concentration response curve (Fig. 3b) to the sigmoidal curve expressed by the formula $y=y_{0}+a /[1+$ $\left.e^{-\left(x-x_{0}\right) / b}\right]$, where $b$ is the Hill coefficient and $x_{0}$ is the $\mathrm{EC}_{50} \mathrm{of} \mathrm{Ca}^{2+}$.

\section{Comparison of glutamate concentration at the synaptic cleft with $\gamma$-DGG}

We omitted 2-chloroadenosine, which we routinely used elsewhere to prevent bursting in slice preparations, from the external solution to increase the overall release probability. To prevent bursting in this condition, we also omitted picrotoxin. We isolated the EPSC from the $\mathrm{GABA}_{\mathrm{A}}$ receptor-mediated inhibitory postsynaptic current by using $5 \mathrm{mM} \mathrm{CsCl}$ and 130 $\mathrm{mM}$ cesium methane-sulfonate, which brings the reversal potential of chloride to $-65 \mathrm{mV}$. We confirmed the lack of $\mathrm{GABA}_{\mathrm{A}}$ receptor-mediated inhibitory postsynaptic current in each experiment by the lack of evoked current after blockade of AMPAR-EPSC with NBQX.

\section{Pre- and postsynaptic double recording from hippocampal CA3 pyramidal cells}

We made paired recordings of pre- and postsynaptic CA3 pyramidal cells in adjacent transfected and untransfected cells, similar to the method describe above for recording from CA1 pyramidal cells, with the following modifications: the extracellular solution contained $1 \mu \mathrm{M}$ 2-chloroadenosine; and the internal solution contained $130 \mathrm{mM}$ potassium gluconate and $20 \mathrm{mM} \mathrm{KCl}$ instead of cesium methanesulfonate and $\mathrm{CsCl}$. We evoked synaptic transmission by a $60-\mathrm{mV}$ depolarization pulse from $-60 \mathrm{mV}$ or $-70 \mathrm{mV}$ with a 2-ms to $4-\mathrm{ms}$ duration to one of the neurons in voltage-clamp mode delivered at $0.1 \mathrm{~Hz}$ while recording postsynaptic EPSCs from the other neuron at $-60 \mathrm{mV}$. We tested synaptic connectivity by applying 50 consecutive paired stimulations (at a 50-ms interval); responses larger than $5 \mathrm{pA}$ occurring within $5 \mathrm{~ms}$ of the onset of either of the pulses were considered evoked unitary EPSCs. If we noted any evoked response during that period, we considered the pair 
synaptically connected. We visually judged the success or failure of the synaptic transmission from 100-150 consecutive evoked EPSC traces. The success rate was calculated by the number of successful transmissions divided by the total number of stimulations.

\section{Supplementary Material}

Refer to Web version on PubMed Central for supplementary material.

\section{Acknowledgments}

We thank G.-S. Liu, I. Ehrlich, K. Kobayashi and T. Takahashi for advice, and J.C. Howard for editing. Supported by RIKEN and The Ellison Medical Foundation (Y.H.), a Special Postdoctoral Researchers Fellowship from RIKEN (K.F.), the Howard Hughes Medical Institute (M.S.) and the US National Institutes of Health (R01 NS045014 to P.S.).

\section{References}

1. Liu G, Choi S, Tsien RW. Variability of neurotransmitter concentration and nonsaturation of postsynaptic AMPA receptors at synapses in hippocampal cultures and slices. Neuron. 1999; 22:395-409. [PubMed: 10069344]

2. Dobrunz LE, Stevens CF. Heterogeneity of release probability, facilitation, and depletion at central synapses. Neuron. 1997; 18:995-1008. [PubMed: 9208866]

3. Rosenmund C, Clements JD, Westbrook GL. Nonuniform probability of glutamate release at a hippocampal synapse. Science. 1993; 262:754-757. [PubMed: 7901909]

4. Conti R, Lisman J. The high variance of AMPA receptor- and NMDA receptor-mediated responses at single hippocampal synapses: evidence for multiquantal release. Proc Natl Acad Sci USA. 2003; 100:4885-4890. [PubMed: 12682300]

5. Matsuzaki M, et al. Dendritic spine geometry is critical for AMPA receptor expression in hippocampal CA1 pyramidal neurons. Nat Neurosci. 2001; 4:1086-1092. [PubMed: 11687814]

6. Shepherd GM, Harris KM. Three-dimensional structure and composition of CA3-4CA1 axons in rat hippocampal slices: implications for presynaptic connectivity and compartmentalization. $\mathbf{J}$ Neurosci. 1998; 18:8300-8310. [PubMed: 9763474]

7. Schikorski T, Stevens CF. Quantitative ultrastructural analysis of hippocampal excitatory synapses. J Neurosci. 1997; 17:5858-5867. [PubMed: 9221783]

8. Sun HY, Lyons SA, Dobrunz LE. Mechanisms of target-cell specific short-term plasticity at Schaffer collateral synapses onto interneurones versus pyramidal cells in juvenile rats. J Physiol (Lond). 2005; 568:815-840. [PubMed: 16109728]

9. Pratt KG, Watt AJ, Griffith LC, Nelson SB, Turrigiano GG. Activity-dependent remodeling of presynaptic inputs by postsynaptic expression of activated CaMKII. Neuron. 2003; 39:269-281. [PubMed: 12873384]

10. Kazama H, Morimoto-Tanifuji T, Nose A. Postsynaptic activation of calcium/calmodulindependent protein kinase II promotes coordinated pre- and postsynaptic maturation of Drosophila neuromuscular junctions. Neuroscience. 2003; 117:615-625. [PubMed: 12617966]

11. Haghighi AP, et al. Retrograde control of synaptic transmission by postsynaptic CaMKII at the Drosophila neuromuscular junction. Neuron. 2003; 39:255-267. [PubMed: 12873383]

12. Zucker RS, Regehr WG. Short-term synaptic plasticity. Annu Rev Physiol. 2002; 64:355-405. [PubMed: 11826273]

13. Irie M, et al. Binding of neuroligins to PSD-95. Science. 1997; 277:1511-1515. [PubMed: 9278515]

14. Chih B, Engelman H, Scheiffele P. Control of excitatory and inhibitory synapse formation by neuroligins. Science. 2005; 307:1324-1328. [PubMed: 15681343] 
15. Ichtchenko K, et al. Neuroligin 1: a splice site-specific ligand for $\beta$-neurexins. Cell. 1995; 81:435443. [PubMed: 7736595]

16. El-Husseini AE, Schnell E, Chetkovich DM, Nicoll RA, Bredt DS. PSD-95 involvement in maturation of excitatory synapses. Science. 2000; 290:1364-1368. [PubMed: 11082065]

17. Scheiffele P, Fan J, Choih J, Fetter R, Serafini T. Neuroligin expressed in nonneuronal cells triggers presynaptic development in contacting axons. Cell. 2000; 101:657-669. [PubMed: 10892652]

18. Dean C, et al. Neurexin mediates the assembly of presynaptic terminals. Nat Neurosci. 2003; 6:708-716. [PubMed: 12796785]

19. Graf ER, Zhang X, Jin SX, Linhoff MW, Craig AM. Neurexins induce differentiation of GABA and glutamate postsynaptic specializations via neuroligins. Cell. 2004; 119:1013-1026. [PubMed: 15620359]

20. Dean C, Dresbach T. Neuroligins and neurexins: linking cell adhesion, synapse formation and cognitive function. Trends Neurosci. 2006; 29:21-29. [PubMed: 16337696]

21. Ehrlich I, Malinow R. Postsynaptic density 95 controls AMPA receptor incorporation during longterm potentiation and experience-driven synaptic plasticity. J Neurosci. 2004; 24:916-927. [PubMed: 14749436]

22. Nakagawa T, et al. Quaternary structure, protein dynamics, and synaptic function of SAP97 controlled by L27 domain interactions. Neuron. 2004; 44:453-467. [PubMed: 15504326]

23. Schnell E, et al. Direct interactions between PSD-95 and stargazin control synaptic AMPA receptor number. Proc Natl Acad Sci USA. 2002; 99:13902-13907. [PubMed: 12359873]

24. Noguchi J, Matsuzaki M, Ellis-Davies GC, Kasai H. Spine-neck geometry determines NMDA receptor-dependent $\mathrm{Ca}^{2+}$ signaling in dendrites. Neuron. 2005; 46:609-622. [PubMed: 15944129]

25. Monyer $\mathrm{H}$, et al. Heteromeric NMDA receptors: molecular and functional distinction of subtypes. Science. 1992; 256:1217-1221. [PubMed: 1350383]

26. Scheuber A, Miles R, Poncer JC. Presynaptic Cav2.1 and Cav2.2 differentially influence release dynamics at hippocampal excitatory synapses. J Neurosci. 2004; 24:10402-10409. [PubMed: 15548655]

27. Oertner TG, Sabatini BL, Nimchinsky EA, Svoboda K. Facilitation at single synapses probed with optical quantal analysis. Nat Neurosci. 2002; 5:657-664. [PubMed: 12055631]

28. Christie JM, Jahr CE. Multivesicular release at Schaffer collateral-CA1 hippocampal synapses. J Neurosci. 2006; 26:210-216. [PubMed: 16399689]

29. Songyang Z, et al. Recognition of unique carboxyl-terminal motifs by distinct PDZ domains. Science. 1997; 275:73-77. [PubMed: 8974395]

30. Debanne D, Gähwiler BH, Thompson SM. Long-term synaptic plasticity between pairs of individual CA3 pyramidal cells in rat hippocampal slice cultures. J Physiol (Lond). 1998; 507:237-247. [PubMed: 9490845]

31. Pavlidis P, Madison DV. Synaptic transmission in pair recordings from CA3 pyramidal cells in organotypic culture. J Neurophysiol. 1999; 81:2787-2797. [PubMed: 10368397]

32. Piomelli D. The molecular logic of endocannabinoid signalling. Nat Rev Neurosci. 2003; 4:873884. [PubMed: 14595399]

33. Chavis $P$, Westbrook G. Integrins mediate functional pre- and postsynaptic maturation at a hippocampal synapse. Nature. 2001; 411:317-321. [PubMed: 11357135]

34. Contractor A, et al. Trans-synaptic Eph receptor-ephrin signaling in hippocampal mossy fiber LTP. Science. 2002; 296:1864-1869. [PubMed: 12052960]

35. Jungling $\mathrm{K}$, et al. $\mathrm{N}$-cadherin transsynaptically regulates short-term plasticity at glutamatergic synapses in embryonic stem cell-derived neurons. J Neurosci. 2006; 26:6968-6978. [PubMed: 16807326]

36. Regalado MP, Terry-Lorenzo RT, Waites CL, Garner CC, Malenka RC. Transsynaptic signaling by postsynaptic synapse-associated protein 97. J Neurosci. 2006; 26:2343-2357. [PubMed: 16495462]

37. Varoqueaux F, et al. Neuroligins determine synapse maturation and function. Neuron. 2006; 51:741-754. [PubMed: 16982420] 
38. Migaud M, et al. Enhanced long-term potentiation and impaired learning in mice with mutant postsynaptic density-95 protein. Nature. 1998; 396:433-439. [PubMed: 9853749]

39. Missler M, et al. a-Neurexins couple $\mathrm{Ca}^{2+}$ channels to synaptic vesicle exocytosis. Nature. 2003; 423:939-948. [PubMed: 12827191]

40. Zhang W, et al. Extracellular domains of a-neurexins participate in regulating synaptic transmission by selectively affecting N- and P/Q-type $\mathrm{Ca}^{2+}$ channels. J Neurosci. 2005; 25:43304342. [PubMed: 15858059]

41. Boucard AA, Chubykin AA, Comoletti D, Taylor P, Südhof TC. A splice code for trans-synaptic cell adhesion mediated by binding of neuroligin 1 to $\alpha$ - and $\beta$-neurexins. Neuron. 2005; 48:229236. [PubMed: 16242404]

42. Dekay JG, Chang TC, Mills N, Speed HE, Dobrunz LE. Responses of excitatory hippocampal synapses to natural stimulus patterns reveal a decrease in short-term facilitation and increase in short-term depression during postnatal development. Hippocampus. 2006; 16:66-79. [PubMed: 16261553]

43. Petralia RS, Sans N, Wang YX, Wenthold RJ. Ontogeny of postsynaptic density proteins at glutamatergic synapses. Mol Cell Neurosci. 2005; 29:436-452. [PubMed: 15894489]

44. Song JY, Ichtchenko K, Südhof TC, Brose N. Neuroligin 1 is a postsynaptic cell-adhesion molecule of excitatory synapses. Proc Natl Acad Sci USA. 1999; 96:1100-1105. [PubMed: 9927700]

45. Yoshii A, Sheng MH, Constantine-Paton M. Eye opening induces a rapid dendritic localization of PSD-95 in central visual neurons. Proc Natl Acad Sci USA. 2003; 100:1334-1339. [PubMed: 12552131]

46. Reyes A, et al. Target-cell-specific facilitation and depression in neocortical circuits. Nat Neurosci. 1998; 1:279-285. [PubMed: 10195160]

47. Koester HJ, Johnston D. Target cell-dependent normalization of transmitter release at neocortical synapses. Science. 2005; 308:863-866. [PubMed: 15774725]

48. Okamoto K, Nagai T, Miyawaki A, Hayashi Y. Rapid and persistent modulation of actin dynamics regulates postsynaptic reorganization underlying bidirectional plasticity. Nat Neurosci. 2004; 7:1104-1112. [PubMed: 15361876]

49. Matsuzaki M, Honkura N, Ellis-Davies GC, Kasai H. Structural basis of long-term potentiation in single dendritic spines. Nature. 2004; 429:761-766. [PubMed: 15190253]

50. Fifková E, Van Harreveld A. Long-lasting morphological changes in dendritic spines of dentate granular cells following stimulation of the entorhinal area. J Neurocytol. 1977; 6:211-230. [PubMed: 856951] 
a

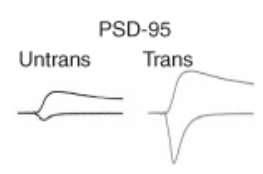

b

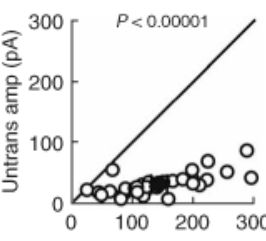

C

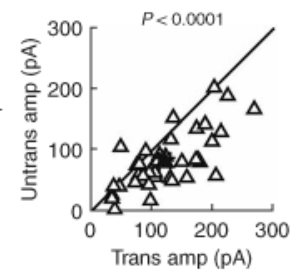

d

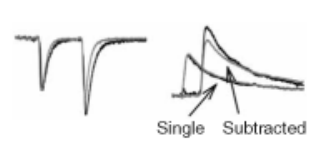

e

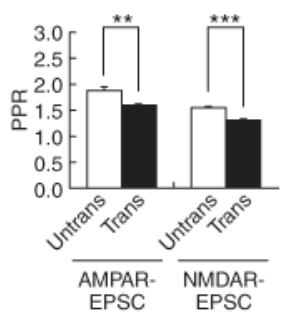

f
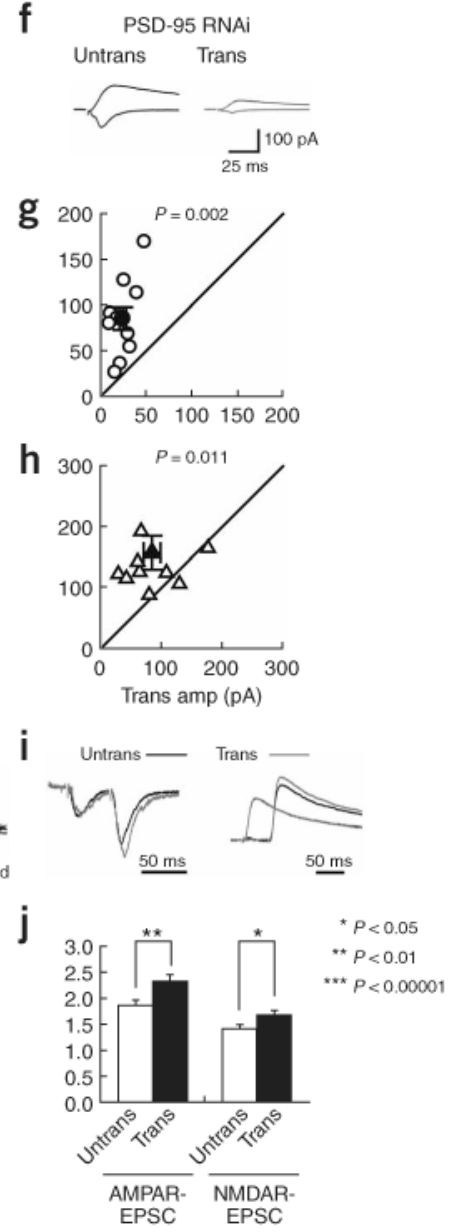

Figure 1.

Effect of postsynaptic PSD-95 on synaptic transmission. Effect of overexpression (a-e) or downregulation $(\mathbf{f}-\mathbf{j})$ of PSD-95 on excitatory synaptic transmission in hippocampal CA1 pyramidal cells. Expression vectors for PSD-95 or short hairpin RNA directed against PSD-95 were transfected together with pEGFP-C1 at a ratio of 9:1 by weight. PDS-95 was assayed $3 \mathrm{~d}$ after transfection; RNAi, after $5 \mathrm{~d}$. An empty pSuper vector used for negative control of RNAi did not show any substantial change in amplitude or PPR ${ }^{22}$ (data not shown). (a,f) Sample EPSC traces mediated by the AMPAR (downward) and NMDAR (upward) from pairs of transfected neurons (Trans) and neighboring untransfected neurons (Untrans). Stimulus artifacts were truncated. (b,c,g,h) EPSC amplitude (amp) for each pair of transfected and neighboring untransfected cells (open symbols); filled symbols indicate the mean. Number of cell pairs: PSD-95, 31 and 42; RNAi, 11 and 10 (for AMPAR-EPSC and NMDAR-EPSC, respectively). (d,i) Sample traces of PPR of AMPAR (left) and NMDAR (right) EPSC. EPSCs normalized to the first EPSC amplitude from transfected neurons (gray) and untransfected neurons (black) are superimposed. Because the first NMDAR-EPSC overlaps with the second EPSC, to measure accurate amplitude of the second EPSC, we 'cancelled' the first EPSC by subtracting the traces receiving a single pulse from those receiving a paired pulse, both normalized to the first response. (e,j) Summary graphs of PPR. The PPR was calculated by dividing the average amplitude of the 
second EPSC by that of the first EPSC. Number of cell pairs: PSD-95, 30 and 27; PSD-95 RNAi, 11 and 10 for AMPA and NMDAR-EPSC, respectively. Error bars, s.e.m. (for all figures). 

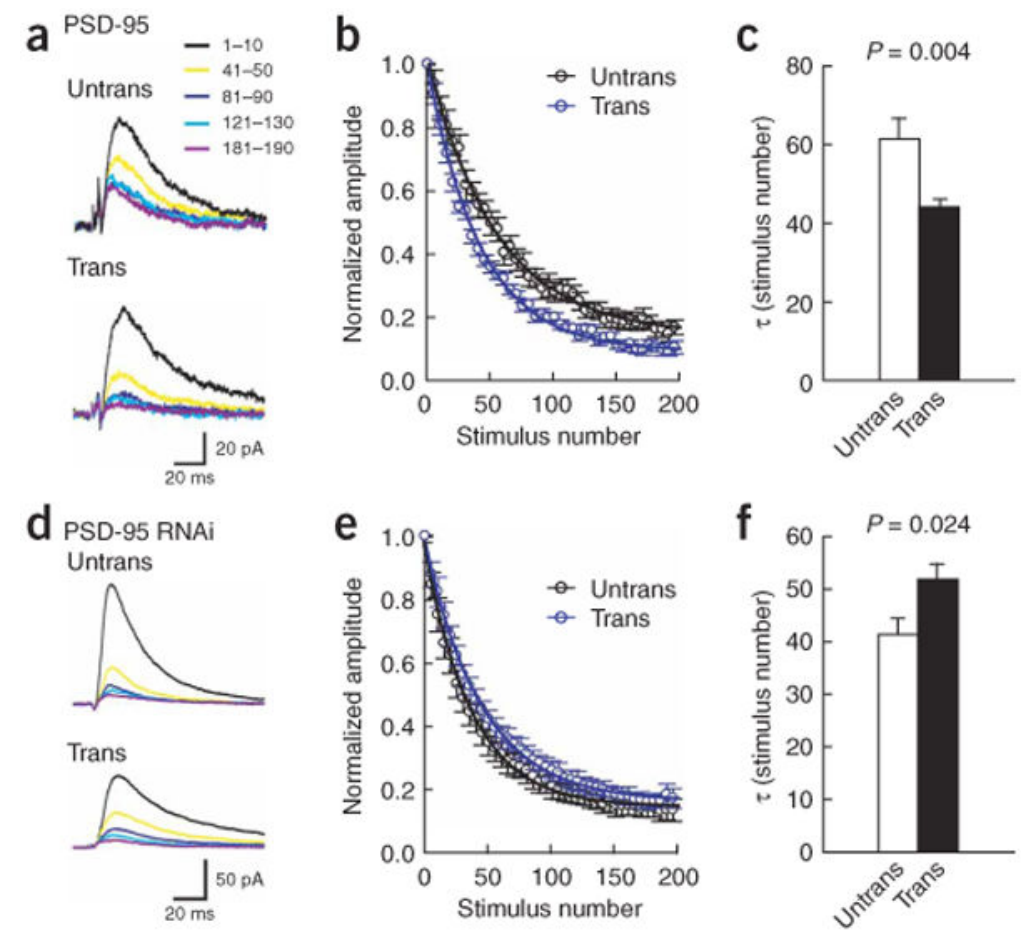

Figure 2.

Postsynaptic PSD-95 regulates release probability in a retrograde way. MK-801, an open channel blocker for NMDA receptor, was used to estimate the presynaptic release probability in hippocampal CA1 pyramidal cells overexpressing PSD-95 (a-c) or expressing short hairpin RNA directed against PSD-95 (d-f). (a,d) Sample traces of NMDAR-EPSCs recorded in the presence of MK-801. Key indicates stimulus sequence numbers included in the averaged traces. The first pulse given in the presence of MK-801 (40 $\mu \mathrm{M})$ was considered 1. (b,e) Average NMDAR-EPSC amplitude during MK-801 perfusion across multiple cells. Amplitudes are the average of each five consecutive EPSCs normalized to that of the first averaged EPSC recorded in the presence of MK-801 in each experiment. Average amplitudes were fitted with single-exponential functions. (c,f) Summary of the effect of MK-801. Data represent the $\tau$ value calculated in each experiment for untransfected and transfected neurons. Decay constant (in number of stimuli): PSD-95-transfected cells, $43.1 \pm 1.9$, and untransfected cells, $59.8 \pm 4.9$ (16 cell pairs); PSD-95 RNAi-treated cells, $51.7 \pm 2.9$, and untreated cells, $41.1 \pm 3.2$ (11 cell pairs). The difference of the decay constant of two untransfected cell groups may be attributable to the different experimental setups and batches of drugs used. 


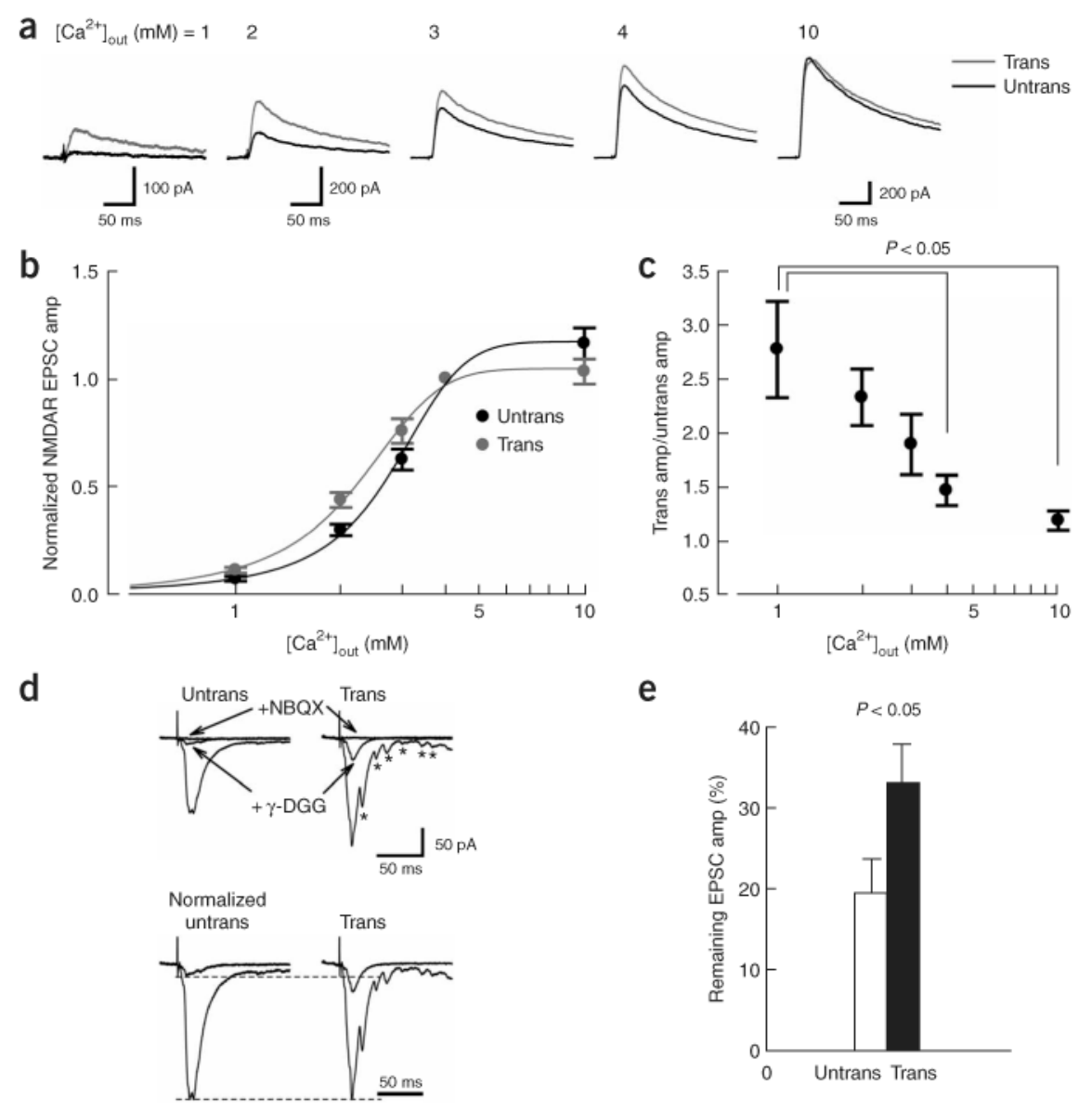

Figure 3.

Postsynaptic PSD-95 changes presynaptic sensitivity to extracellular $\mathrm{Ca}^{2+}$. Pairs of neurons, one transfected with PSD-95 and the other untransfected were recorded simultaneously. (ac) NMDAR-EPSC amplitudes at various concentrations of extracellular $\mathrm{Ca}^{2+}\left(\left[\mathrm{Ca}^{2+}\right]_{\text {out }}\right)$. (a) Sample NMDAR-EPSC traces for pairs of transfected neurons (gray) and neighboring untransfected neurons (black) at five different extracellular $\mathrm{Ca}^{2+}$ concentrations. All traces are from the same pair of neurons In the presence of $4 \mathrm{mM} \mathrm{Mg}^{2+}$ and $1 \mu \mathrm{M} 2-$ chloroadenosine. (b) Summary of the relationship between extracellular $\mathrm{Ca}^{2+}$ concentration and NMDAR-EPSC amplitude. EPSCs were normalized to the EPSC amplitude at $4 \mathrm{mM}$ $\mathrm{Ca}^{2+}$ for transfected cells (gray) and untransfected cells (black). The $\mathrm{Ca}^{2+}$-release relationship for transfected and untransfected cells was fitted to a sigmoidal curve. Number of cell pairs: $1 \mathrm{mM} \mathrm{Ca}^{2+}, 7 ; 2 \mathrm{mM} \mathrm{Ca}^{2+}, 15 ; 3 \mathrm{mM} \mathrm{Ca}^{2+}, 13 ; 4 \mathrm{mM} \mathrm{Ca}^{2+}, 19 ; 10 \mathrm{mM} \mathrm{Ca}^{2+}$, 15. (c) Ratio of amplitude from neurons transfected with PSD-95 to that from untransfected cells. (d,e) Increase in cleft concentration of the low-affinity antagonist for AMPAR $\gamma$-DGG in neurons expressing PSD-95. (d) Top, superimposed sample traces of AMPAR-EPSC with or without $\gamma$-DGG; bottom, superimposed sample traces normalized to the peak amplitude of the traces before the application of $\gamma$-DGG. *, polysynaptic EPSCs. (e) Summary of remaining fraction of EPSC after the application of $\gamma$-DGG. Number of cell pairs $=9$. 

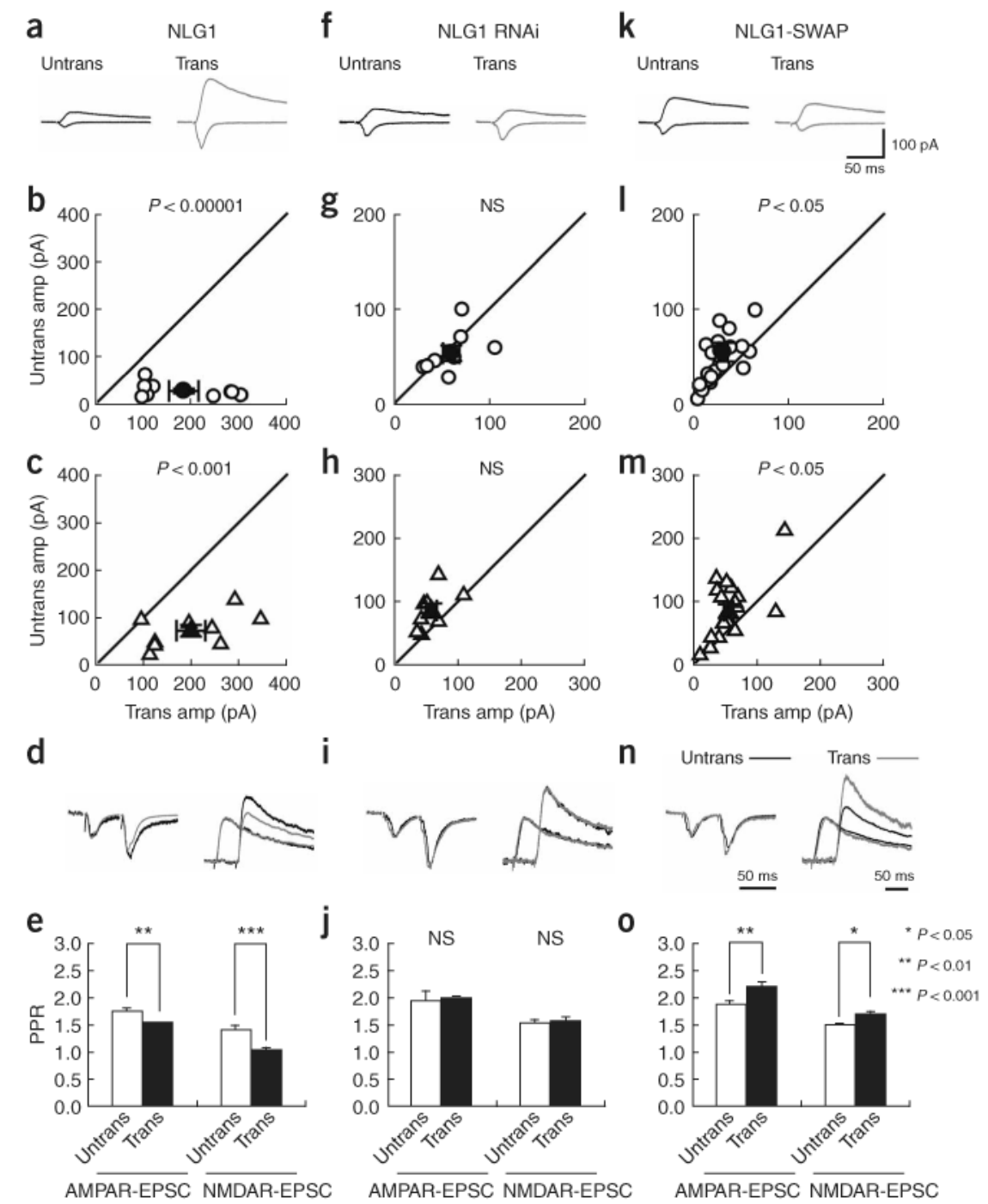

Figure 4.

Effect of postsynaptic NLG1 on synaptic transmission. Effect of overexpression of NLG1 $(\mathbf{a}-\mathbf{e})$ or of NLG1 downregulation by RNAi $(\mathbf{f}-\mathbf{j})$ or with the dominant negative form NLG1SWAP (k-o). Test constructs were transfected together with pEGFP-C1 at a ratio of 9:1. Experiments with NLG1 were assayed 3-4 d after transfection; those with RNAi and NLG1SWAP, after 4-5 d. (a,f,, $\mathbf{k})$ Sample EPSC traces. $(\mathbf{b}, \mathbf{c}, \mathbf{g}, \mathbf{h}, \mathbf{l}, \mathbf{m})$ Plots of AMPAR-EPSC amplitudes (b,g,l) and NMDAR-EPSC amplitudes $(\mathbf{c}, \mathbf{h}, \mathbf{m})$. Number of cell pairs: NLG1, 9 and 9; NLG1 RNAi, 8 and 8; NLG1-SWAP, 22 and 19 for AMPA and NMDAR-EPSC, respectively. (d,i,n) Normalized sample trace of the PPR of the AMPAR-EPSC (left) and NMDAR-EPSC (right). (e,j,, $\mathbf{o})$ Summary of PPRs. Number of cell pairs: NLG1, 9 and 9; NLG1 RNAi, 8 and 8; NLG1-SWAP, 22 and 19. NS, not significant. See Figure 1 for other details. 

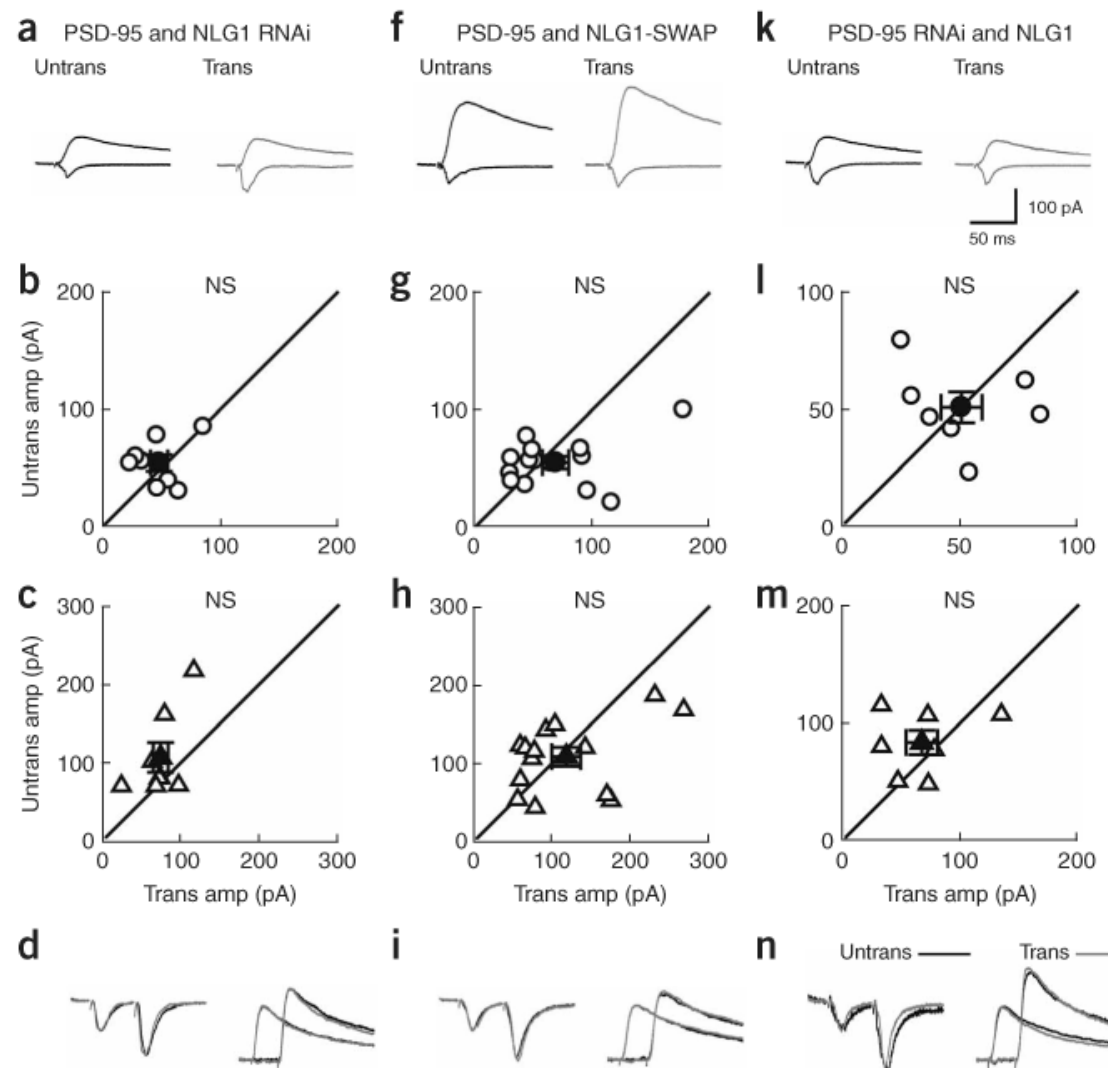

i
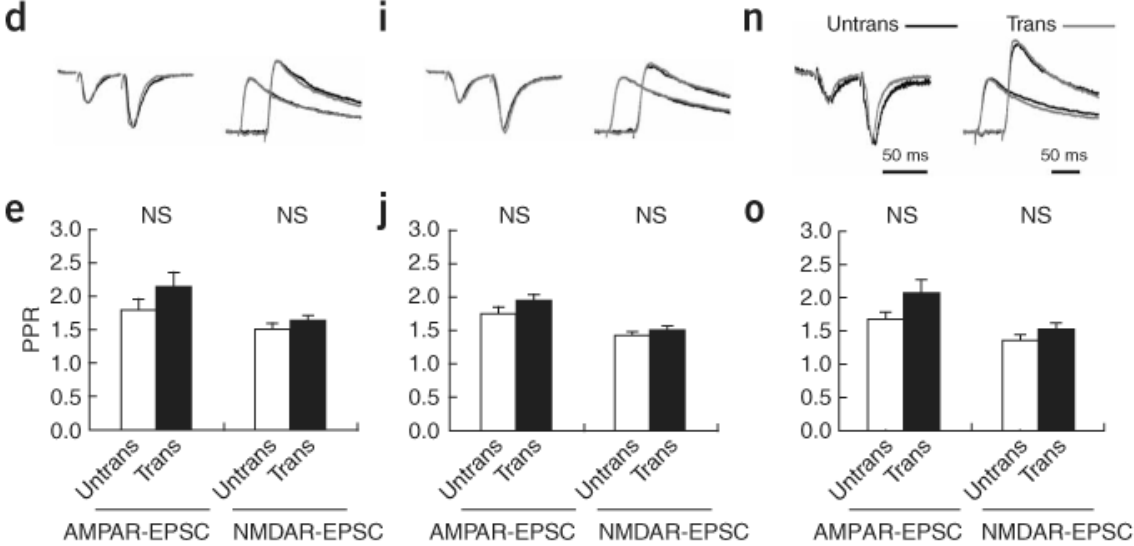

Figure 5.

Interactions between PSD-95 and NLG1 are necessary for both the pre- and postsynaptic effect. Blockade of the effect of PSD-95 with NLG1-RNAi (a-e) or NLG1-SWAP (f-j) and of NLG1 with PSD-95-RNAi (k-o). In a-e, we cotransfected expression vectors for PSD-95, NLG1 shRNA and pEGFP-C1; in $\mathbf{f}-\mathbf{j}$, expression vectors for PSD-95, NLG1SWAP and pEGFP-C1; in k-o, expression vectors for NLG1, PSD-95 shRNA and pEGFP$\mathrm{C} 1$, at a ratio of 9:9:2 or 3:6:1 by weight of the DNA constructs. Because results were similar at different ratios, they are combined. Empty RNAi vector (pSuper) did not block the effect of NLG1 (data not shown). Cells were assayed 3-4 d after transfection. (a,f,k) Sample EPSC traces. (b,c,g,h,l,m) Plots of AMPAR-EPSC amplitudes (b,g,l) and NMDAR-EPSC amplitudes $(\mathbf{c}, \mathbf{h}, \mathbf{m}) .(\mathbf{d}, \mathbf{i}, \mathbf{n})$ Normalized sample traces of the PPR of the AMPAR-EPSC (left) and NMDAR-EPSC (right). (e,j,o) Summary of PPRs. Number of cell pairs: PSD-95 and NLG1 RNAi, 8 and 8; PSD-95 and NLG1-SWAP, 14 and 14; PSD-95 RNAi and NLG1, 7 and 7. See Figure 1 for other details. 
a

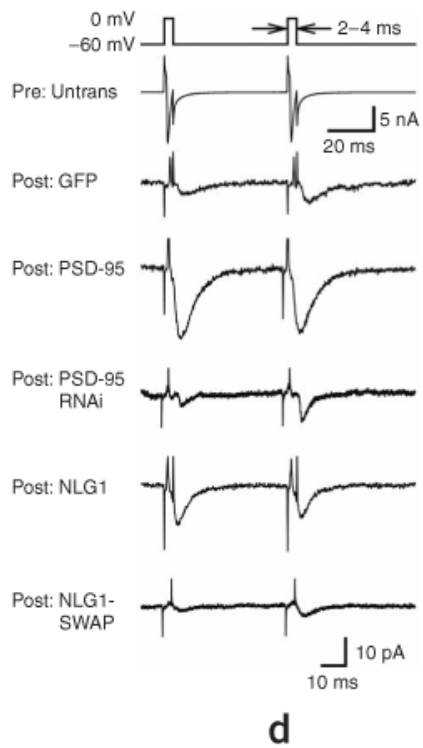

C

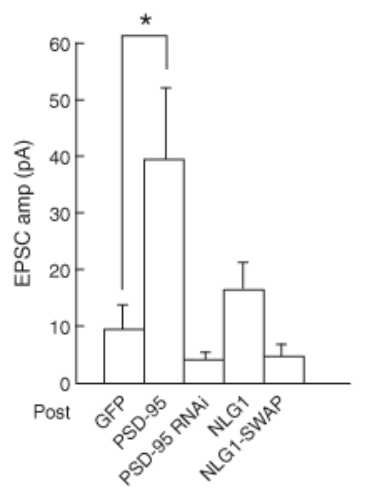

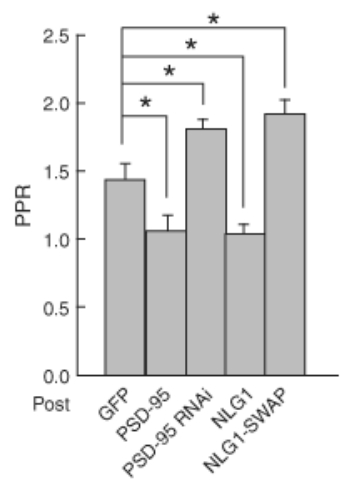

b

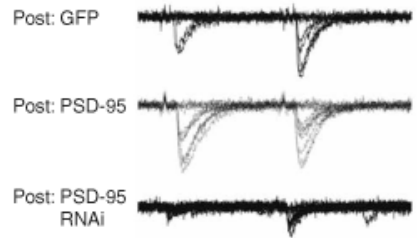

Post: NLG1

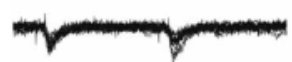

Post: NLG1

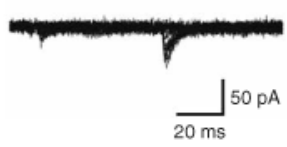

Figure 6.

Postsynaptic PSD-95 and NLG regulates the release probability in a retrograde way in CA3CA3 pyramidal cell synapses. Cells were transfected with PSD-95 and or were treated with PSD-95 RNAi and were analyzed as described in Figure 1. NLG1 and NLG1-SWAP were transfected and analyzed, as described in Figure 4. Controls are neuronal pairs expressing GFP postsynaptically. NLG1-SWAP, pGW1 empty vector and pEGFP-C1 were transfected together at a ratio of 9:9:2. Pre, presynaptic; Post, postsynaptic. (a) Averaged sample

AMPAR-EPSC traces (bottom traces) induced by two presynaptically applied depolarization commands (top). Second from top, presynaptic action current. (b) Ten consecutive AMPAR-EPSC traces, superimposed. The heterogeneity in amplitude for a single pair is probably because more than one connection is often made between a pair of CA3 cells ${ }^{31}$. Alternatively, it may be due to a difference in the number of released vesicles. (c-e) Summary of AMPAR-EPSC amplitude (c), AMPAR-PPR (d) and success rate of synaptic transmission (e). Number of cell pairs used for recording: PSD-95, 25; PSD-95 RNAi, 10; NLG1, 12; NLG1-SWAP, 8; GFP, 13. Pairs of neurons found to be synaptically connected: postsynaptic GFP expression, 28.9\%; postsynaptic PSD-95-transfected pairs, 35.7\%;

PSD-95 RNAi, 15\%; NLG1, 76.5\%; NLG1-SWAP, $14.3 \%$. 
a

Pre: GFP

.

Pre: BNixn

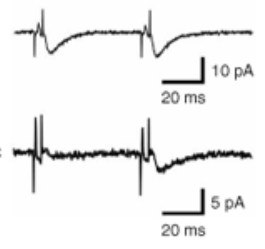

Pre: BNnnnsC b

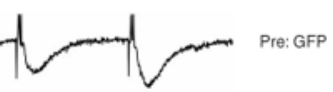

Pre: BNrxn

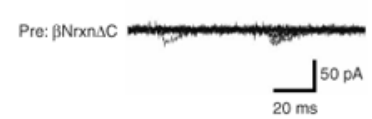

c

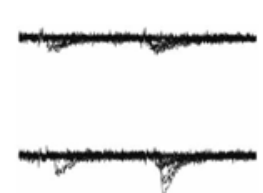

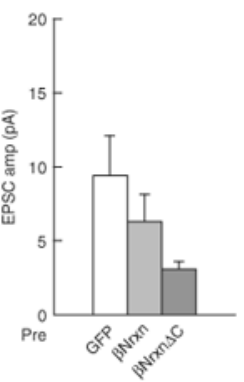

d

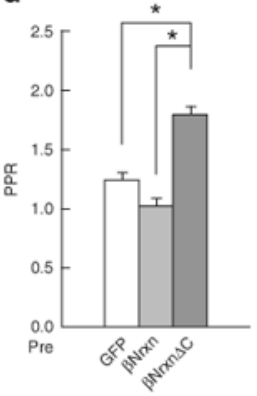

e $\quad \cdot P<0.05$

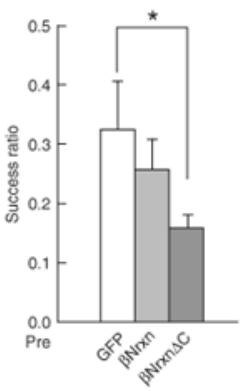

Figure 7.

Reducing presynaptic $\beta$ Nrxn function decreases the release probability. The effect of presynaptic overexpression of $\beta \operatorname{Nrxn}$ or $\beta \operatorname{Nrxn} \Delta \mathrm{C}$. The expression vectors for $\beta \mathrm{Nrxn}$ or $\beta N r x n \Delta C$ were cotransfected with empty pGW1 and pEGFP-C1 at a ratio of 1:2:2 by weight of the DNA constructs; cells were assayed 1-2 d after transfection. Presynaptic neurons transfected with GFP were used as controls. (a,b) Averaged (a) and superimposed (b) sample AMPAR-EPSC traces. (c-e) Summary of AMPAR-EPSC amplitude (c), AMPAR PPR (d) and success ratio of synaptic transmission (e). Number of neurons: $\beta N r x n, 12$; $\beta N r x n \Delta C, 10$. Pairs of neurons found to be synaptically connected: presynaptic GFP expression, $22.2 \%$; presynaptic $\beta \mathrm{Nrxn} \Delta \mathrm{C}$ expression, $29.3 \%$; presynaptic $\beta \mathrm{Nrxn}$ transfection, $22.0 \%$. 